\title{
GPX2 promotes development of bladder cancer with squamous cell differentiation through the control of apoptosis
}

\author{
Taku Naiki,1,2, Aya Naiki-Ito ${ }^{1}$, Keitaro Iida², Toshiki Etani², Hiroyuki Kato ${ }^{1}$, Shugo \\ Suzuki ${ }^{1}$, Yoriko Yamashita ${ }^{1}$, Noriyasu Kawai ${ }^{2}$, Takahiro Yasui ${ }^{2}$ and Satoru \\ Takahashi ${ }^{1}$ \\ ${ }^{1}$ Department of Experimental Pathology and Tumor Biology, Nagoya City University, Graduate School of Medical Sciences, \\ Nagoya, Japan \\ ${ }^{2}$ Department of Nephro-Urology, Nagoya City University, Graduate School of Medical Sciences, Nagoya, Japan \\ Correspondence to: Aya Naiki-Ito, email: ayaito@med.nagoya-cu.ac.jp \\ Keywords: GPX2; oxidative stress; bladder cancer; squamous differentiation \\ Received: October 27, $2017 \quad$ Accepted: February 27, $2018 \quad$ Published: March 23, 2018 \\ Copyright: Naiki et al. This is an open-access article distributed under the terms of the Creative Commons Attribution License 3.0 \\ (CC BY 3.0), which permits unrestricted use, distribution, and reproduction in any medium, provided the original author and source \\ are credited.
}

\section{ABSTRACT}

Herein, we elucidated the molecular mechanisms and therapeutic potential of glutathione peroxidase 2 (GPX2) in bladder cancer. GPX2 expression gradually increased during progression from normal to papillary or nodular hyperplasia (PNHP) and urothelial carcinoma (UC) in a rat $\mathrm{N}$-butyl-N-(4-hydroxybutyl) nitrosamine (BBN)induced bladder carcinogenesis model. GPX2 overexpression was more marked in UC with squamous differentiation (SqD) than in pure UC. Clinical intraepithelial lesions of papillary UC and invasive UC with SqD also had strong GPX2 expression in human radical cystectomy specimens. In addition, prognostic analysis using transurethral specimens revealed that low expression level of GPX2 predicted poor prognosis in patients with pure UC. Further, UC cell lines, BC31 and RT4, cultured in vitro also overexpressed GPX2. Knock-down of GPX2 induced significant inhibition of intracellular reactive oxygen species (ROS) production, in addition to significant growth inhibition and increased apoptosis with activation of caspase 3 or 7 in both BC31 and RT4 cells. Interestingly, tumor growth of BC31 cells subcutaneously transplanted in nude mice was significantly caused the induction of apoptosis, as well as inhibition of angiogenesis and SqD by GPX2 down-regulation. Our findings demonstrated that GPX2 plays an important role in bladder carcinogenesis through the regulation of apoptosis against intracellular ROS, and may be considered as a novel biomarker or therapeutic target in bladder cancer.

\section{INTRODUCTION}

Bladder cancer is the ninth most common cancer, with an estimated global incidence of 429,000 in 2012 [1], and the development of new treatment modalities is impending based on the clarification of therapeutic molecular mechanisms. Urothelial carcinoma (UC) of the bladder, accounting for about $90 \%$ of all bladder tumors, is the second most common urological malignancy after prostate cancer. The most important risk factors for bladder cancer are smoking, aging, and genetic predisposition $[2,3]$, and solid primary cancers arise via a multi-step process of accumulated genetic alterations [2]. However, the molecular mechanisms of bladder carcinogenesis are not yet clearly elucidated.

Recent evidence suggests that oxidative stress induced by the above-mentioned risk factors is involved in the progression of bladder carcinogenesis. Thus, there is heightened interest in the role of oxidative stress and the status of antioxidant agents in bladder cancer [4-6], as well as antioxidant mechanisms that can be manipulated as therapeutic targets for cancer prevention or as prognostic biomarkers [7-10]. The glutathione redox system is the most important antioxidant agent that protects against 
intracellular damage induced by oxidative stress in humans [11, 12]. Glutathione peroxidase (GPX), a selenoprotein and a member of the glutathione peroxidase family, is a key enzyme of the glutathione redox system. So far, eight different isoforms of GPX have been reported in mammals $[12,13]$. They appear to have antioxidant function at several locations and cellular components. In particular, GPX1 is ubiquitously found in the cytosol and mitochondria of liver, lung kidney, and red blood cells, and GPX2 is mainly expressed in the cytosol of mammary tissue and the gastrointestinal tract, as well as in the human liver $[11,14,15]$.

GPX2 is known to reduce hydrogen peroxide and superoxide radical, and is considered to play a major role in the antioxidant defense system, including protection against oxidative damage from risk factors like food consumption, and smoking [11, 16-19]. On the other hand, GPX2 has also been shown to contribute to the progression of malignant tumor [20]. We had previously shown that GPX2 is overexpressed in breast [21], liver [22], and castration-resistant prostate cancers [23], and clarified the molecular mechanisms underlying its regulation in cancer proliferation, in addition to its significance as a therapeutic target in these malignant tumors. In this report, we extended our investigations based on these previous findings, and elucidated the role and prognostic significance of GPX2 in bladder cancer.

\section{RESULTS}

\section{GPX2 expression in a rat model of bladder carcinogenesis and in human radical cystectomy specimens}

We first examined the status of GPX2, using specimens obtained from a bladder carcinogenesis model induced by treatment of rats with N-butyl$\mathrm{N}$-(4-hydroxybutyl) nitrosamine (BBN) and $0.05 \%$ phenylethyl isothiocyanate (PEITC). We found by immunohistochemical analyses that the protein expression level of Gpx2 in the normal epithelium of the BBN + PEITC-treated group was significantly elevated as compared to that of the non-treated control group (Figure 1A-1D, 1K). Further, the expression level of Gpx2 was significantly higher in papillary or nodular hyperplasia (PNHP) and pure urothelial carcinoma (UC) lesions than in the normal epithelium of BBN + PEITC-treated rats. In addition, Gpx2 expression was demonstrated to be highest in UC with squamous differentiation (SqD) (Figure 1E-1J, 1L). However, in the analyses using clinical radical cystectomy specimens, the expression level of GPX2 was variable. In non-invasive papillary UC tumors, its expression was high (Figure 2A, 2D) while it was low in advanced invasive specimens (Figure 2B, 2E). Interestingly, a high level of GPX2 expression was detected in $\mathrm{UC}$ with $\mathrm{SqD}$ as observed in the animal model (Figure 2C, 2F). These results suggested that GPX2 expression was induced in urinary epithelium in the initiation phase, was down-regulated in the promotion phase, and was involved in SqD of advanced UC.

\section{GPX2 expression and prognostic analysis of pure UC patients using transurethral resection (TUR) specimens}

In both the animal model and human radical cystectomy specimens, GPX2 expression was upregulated in pure UC. Therefore, immunohistochemical and prognostic analyses were performed using 169 TUR specimens. The clinical course of these patients with bladder cancer is listed in Table 1 . We found that the expression of GPX2 was significantly higher in non-invasive bladder cancer patients than in invasive patients, and was inversely correlated with the Ki67 index and P53 positivity (Table 1, Figure 3A-3H). Further, pathological T2 or higher stage patients had significantly lower GPX2 expression as well as higher Ki67 index and P53 positivity than Ta/T1 stage patients (Figure 3I$3 \mathrm{~K})$. In addition, the patients with a high level of GPX2 expression in their TUR specimen showed significantly better progression-free survival (PFS), cancer-specific survival (CSS), and overall survival (OS) than those with low level of GPX2 expression (Figure 3L-3N). Table 2 summarizes the prognostic factors for PFS after TUR as determined by univariate and multivariate analyses. Higher GPX2 expression in the TUR specimen had the strongest association with better prognosis after TUR by both univariate and multivariate analyses.

\section{GPX2 expression in bladder cancer cell lines, and $G P X 2$ siRNA transfection in RT4 cells}

To elucidate the mechanisms of tumorigenic ability induced by GPX2, we explored the role of GPX2 on cell proliferation in human UC cell lines, of which RT4 had significantly higher expression of GPX2 than the other UC cell lines, T24, 5637, and TCCSUP (Figure 4A). Therefore, we used RT4 cells for further analyses. Knockdown of GPX2 by two different siRNAs in RT4 was confirmed by quantitative RT-PCR (qRT-PCR) (Figure 4B). Cell proliferation of RT4 cells was significantly suppressed by GPX2 inhibition as compared to the negative control (NC) (Figure 4D). To understand the underlying growth regulatory mechanism by GPX2, we determined whether the levels of proteins associated with cell cycle and apoptosis were altered by inhibition of GPX2 in RT4 cells. Suppression of GPX2 resulted in marked induction of cleaved caspase 7 , while no changes in the expression of cell cycle-related proteins were observed (Figure 4C). Therefore, flow cytometry analysis by the Guava ${ }^{\circledR}$ apoptosis assay was performed, and we found that there appeared to be a significant accumulation 
of apoptotic cells following GPX2 inhibition (Figure 4E). Furthermore, dichloro-dihydro-fluorescein diacetate (DCFH-DA) assay revealed that intracellular ROS level was significantly decreased in the Gpx2-siRNA transfected group as compared to the NC (Figure 4F). These results suggested that GPX2 is involved in the maintenance of cell proliferation by protection against caspase-dependent apoptosis via ROS regulation in RT4 cells.
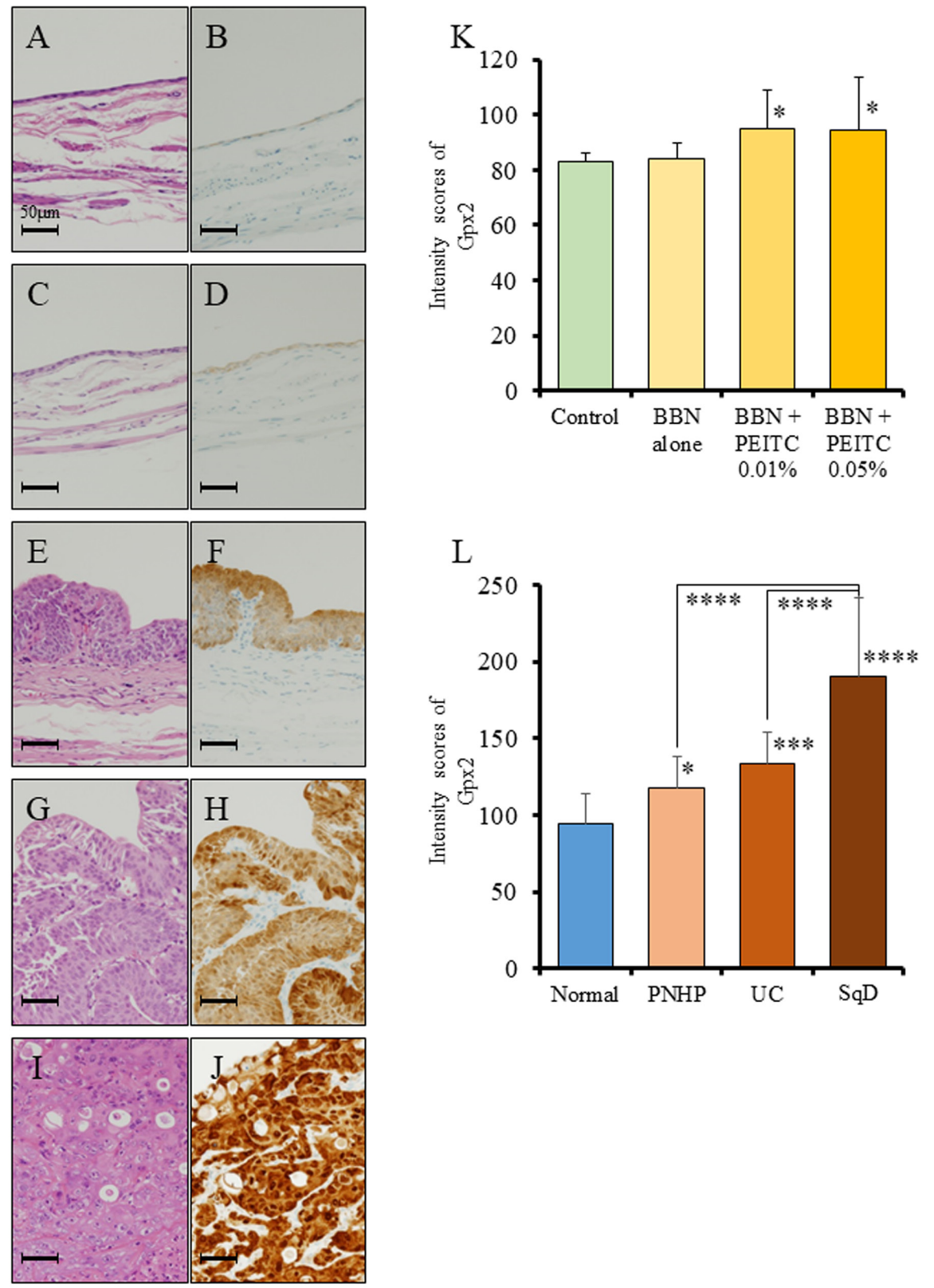

Figure 1: Analysis of Gpx2 expression by immunohistochemistry using a rat bladder carcinogenesis model. (A-D) HE staining $(\mathrm{A}, \mathrm{C})$ and representative immunohistochemistry for $\mathrm{Gpx} 2(\mathrm{~B}, \mathrm{D})$ in normal bladder epithelium obtained from the non-treated group (A, B) and BBN + 0.05\% PEITC-treated (C, D) rats. (E, F) HE staining (E) and representative immunohistochemistry for Gpx2 (F) in PNHP of the bladder obtained from BBN $+0.05 \%$ PEITC-treated rats. $(\mathbf{G}, \mathbf{H})$ HE staining $(\mathrm{G})$ and representative immunohistochemistry for $\mathrm{Gpx} 2(\mathrm{H})$ in papillary pure UC of the bladder obtained from BBN $+0.05 \%$ PEITC-treated rats. (I, J) HE staining (I) and representative immunohistochemistry for Gpx2 (J) in UC with squamous cell differentiation (SqD) of the bladder obtained from BBN $+0.05 \%$ PEITCtreated rat. (K) Quantification of intensity of Gpx2 expression in normal epithelium. In BBN + PEITC-treated rats, the expression level of Gpx2 was significantly increased as compared to that in the control non-treated group (Control). Mean $\pm \mathrm{SD}$; ${ }^{*} p<0.05$. (L) Quantification of intensity of Gpx2 expression in the BBN $+0.05 \%$ PEITC-treated group. The expression level of Gpx 2 was significantly increased in PNHP, UC, and SCC as compared to normal epithelium. In addition, the expression level of Gpx2 was the highest in UC with SqD. Mean $\pm \mathrm{SD} ;{ }^{*} p<0.05,{ }^{* * *} p<0.001,{ }^{* * * *} p<0.0001$. Nuclei were counterstained with hematoxylin. 


\section{Gpx2 siRNA transfection and ROS signals in BC31 cells}

In our previous study, we demonstrated that GPX2 promotes cell proliferation by control of oxidative stress using GPX2 knock-down analyses. To examine the role of GPX2 on cell proliferation and oxidative stress in UC, $\mathrm{BC} 31$ cells, which is a rat $\mathrm{UC}$ cell line with squamous characterization [24, 25], was used. qRT-PCR analysis revealed that Gpx2 mRNA levels were inhibited following transfection with two different siRNAs for 2 days (Figure 5A). Similar to RT4 cells, cell proliferation of BC31 cells was significantly decreased by inhibition of GPX2 as compared to NC (Figure 5B). In addition, Gpx2 silencing induced a significant increase in apoptosis with activation of caspases 3 and 7 by western blotting and flow cytometry (Figure 5C, 5E). Further, DCFH-DA assay also revealed that intracellular ROS level was significantly decreased in the Gpx2-siRNA transfected group as compared to the NC (Figure 5D). These results suggest that ROS accumulation induced by Gpx2 overexpression is necessary for maintaining cell growth in $\mathrm{BC} 31$ cells.

\section{In vivo regulation by Gpx2 of growth of tumors with squamous cell differentiation derived from $\mathrm{BC} 31$ cells}

To evaluate the role of GPX2 in growth of UC with $\mathrm{SqD}, G p x 2$-siRNA transfected $\mathrm{BC} 31$ cells were subcutaneously transplanted in nude mice. Knock-down of Gpx2 significantly inhibited tumor growth of $\mathrm{BC} 31$ cells as compared to the NC (Figure 6A-6D, 6K). To verify the results of the in vitro study, the in vivo tumor suppressive mechanisms by Gpx2 attenuation were examined using TUNEL assay. Down-regulation of Gpx2 significantly increased the proportion of TUNEL-positive apoptotic cells as compared with NC (Figure 6E-6F, 6L). In addition, we examined vascular density in the tumors by immunohistochemistry for CD31. We found that vessel density was significantly decreased in the Gpx2siRNA group than in the NC group (Figure 6G-6H, 6M). We further examined the abundance of cancer cells with squamous differentiation. Immunohistochemical analyses for cytokeratin (CK) 14 revealed that its expression was significantly decreased in Gpx2-suppressed tumors as compared to $N C$ ones (Figure 6I-6J, 6N). These results suggested that attenuation of Gpx2 suppressed tumor growth of UC with $\mathrm{SqD}$ through the induction of apoptosis, as well as inhibition of angiogenesis and squamous differentiation.

\section{DISCUSSION}

To our knowledge, only one previous report has been published regarding the expression level of GPX2 in bladder cancer [26]. However, the stage-dependent expression alteration and detailed molecular mechanisms of GPX2 during bladder carcinogenesis had not been
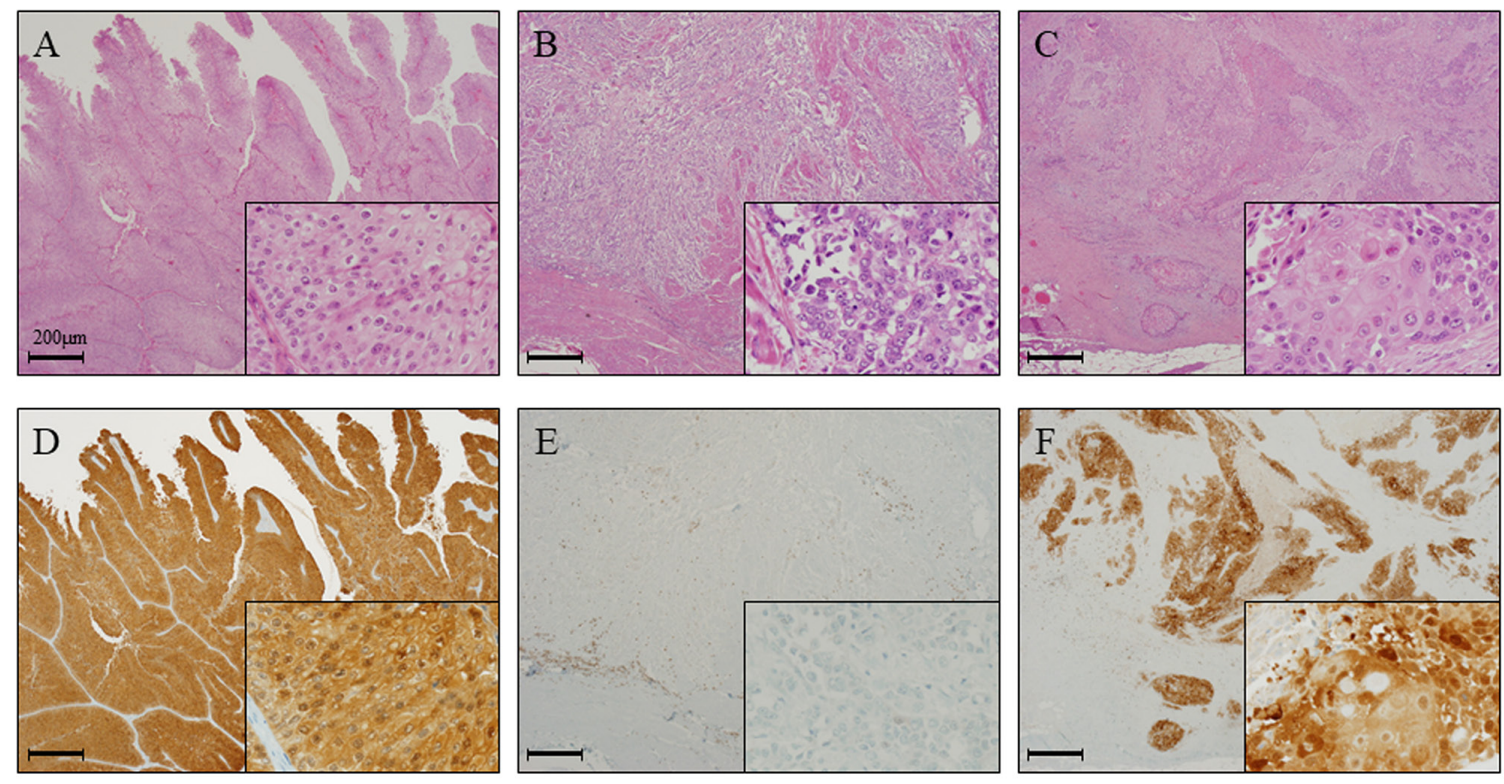

Figure 2: GPX2 expression is elevated in papillary urothelial carcinoma and squamous cell differentiation in radical cystectomy specimens. (A, D) HE staining (A) and representative immunohistochemistry for GPX2 (D) in papillary UC of the bladder, which showed high expression level similar to the results from the analyses using the animal model. (B, E) HE staining (B) and representative immunohistochemistry for GPX2 (E) in advanced invasive UC of the bladder, which showed very low expression level. (C, F) HE staining (C) and representative immunohistochemistry for GPX2 (F) in UC with SqD of the bladder, which demonstrated high expression level similar to the results from the analyses using the animal model. Nuclei were counterstained with hematoxylin. 

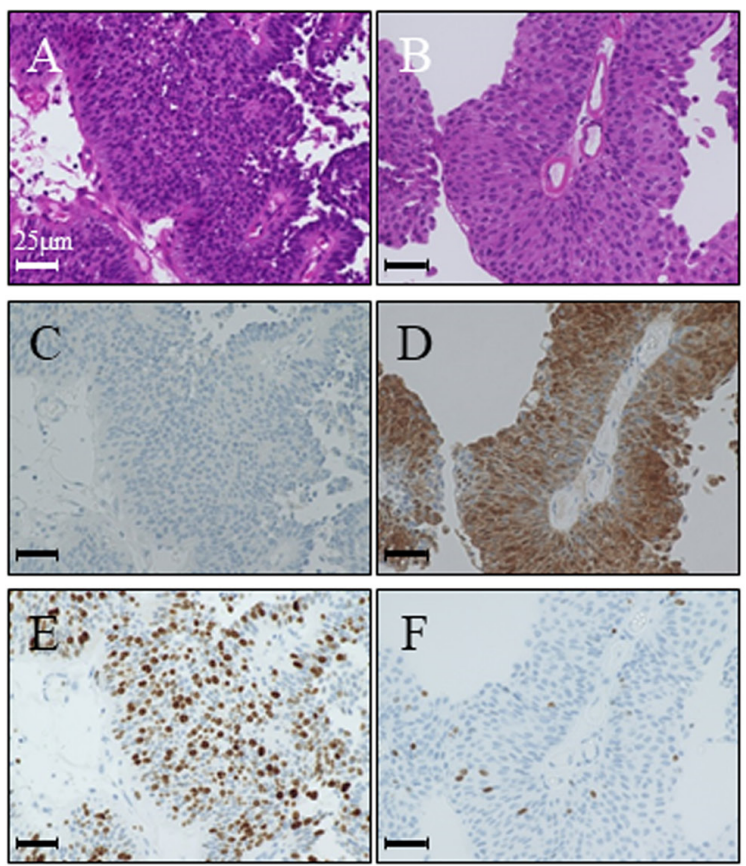

$\mathrm{G}$

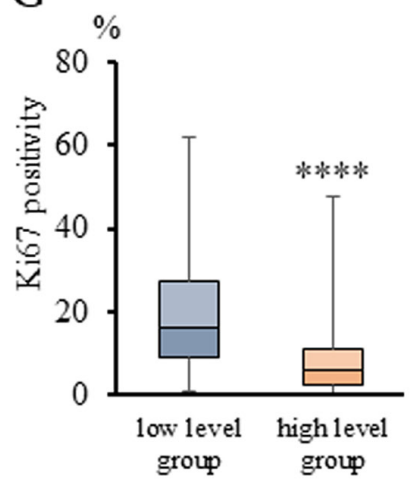

$\mathrm{H}$

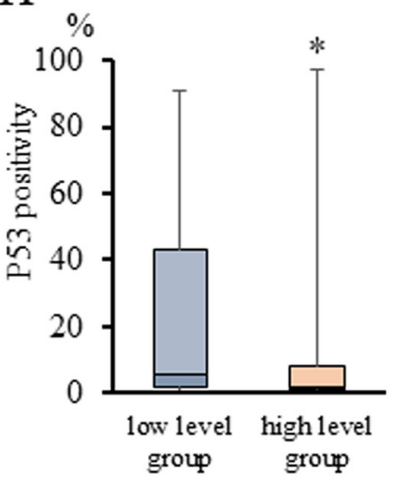

I

I
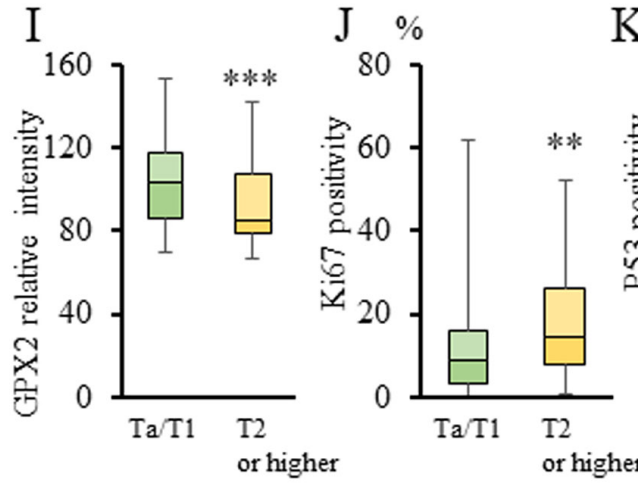
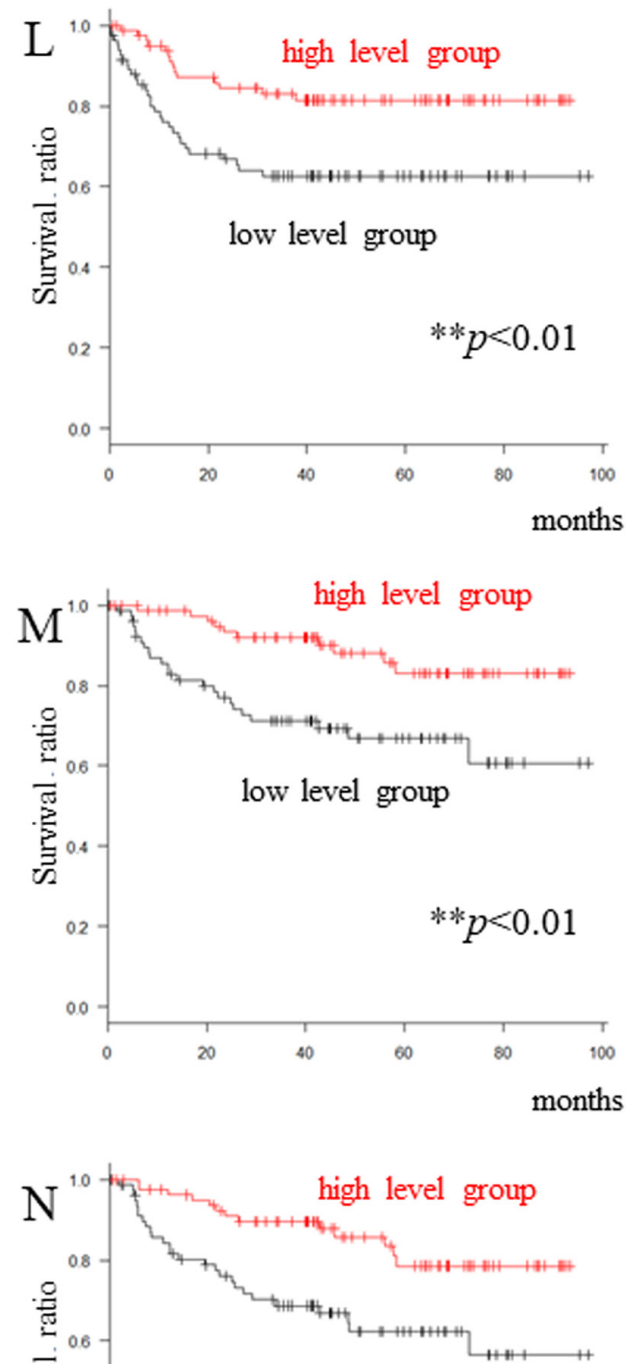

low level group

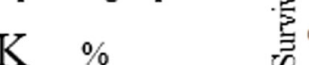

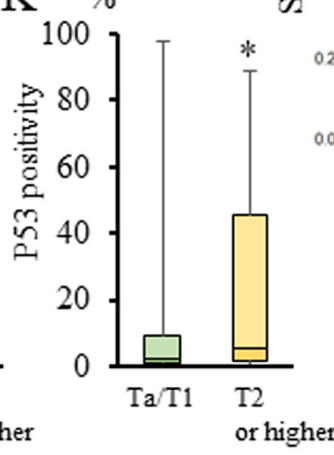

$* * p<0.01$

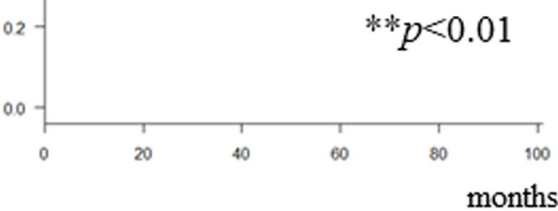

Figure 3: GPX2 and Ki67 expression, and prognostic analysis in transurethral resection (TUR) specimens. (A-F) HE staining (A, B) and representative immunohistochemistry for GPX2 (C, D) and Ki67 (E, F) In TUR specimens. (G, H) Ki67 positivity $(\mathrm{G})$ and P53 positivity $(\mathrm{H})$ in the low (average intensity score $<96.7)$ and high (average intensity score $\geq 96.7)$ GPX2 expression groups according to the expression in TUR specimens. ${ }^{*} p<0.05,{ }^{* * * *} p<0.001$ (I-K) Comparison of GPX2 expression score (I), Ki67 positivity (J), and P53 positivity (K) in TUR specimens between cases of stage Ta/T1, and T2 or higher. ${ }^{*} p<0.05,{ }^{* *} p<0.01,{ }^{* * *} p<0.001$ (L-N) Progression-free survival (L), cancer-specific survival $(\mathrm{M})$, and overall survival $(\mathrm{N})$ in patients between the low $(\mathrm{n}=83)$, and high $(\mathrm{n}=86)$ GPX2 expression groups. ${ }^{* *} p<0.01$. 
Table 1: Patients' characteristics

\begin{tabular}{|c|c|c|c|c|}
\hline \multirow[t]{2}{*}{ Characteristics } & & \multicolumn{2}{|c|}{ GPX2 expression } & \multirow[t]{2}{*}{$p$-value } \\
\hline & & Low level group $(n=83)$ & High level group $(n=86)$ & \\
\hline \multicolumn{2}{|l|}{ Median age, years (range) } & $72(37-90)$ & $70(38-87)$ & n.s. \\
\hline \multirow[t]{2}{*}{ Sex } & Male $(\%)$ & $65(78.3)$ & $63(73.3)$ & n.s. \\
\hline & Female $(\%)$ & $18(21.7)$ & $23(26.7)$ & \\
\hline \multirow[t]{2}{*}{ Non-invasive or invasive } & Non-invasive $(\%)$ & $3(0.6)$ & $21(24.4)$ & $<0.0001^{* * * * *}$ \\
\hline & Invasive $(\%)$ & $80(96.4)$ & $65(75.6)$ & \\
\hline \multicolumn{2}{|c|}{ Size of main tumor, mm (range) } & $21(7-100)$ & $21(7-65)$ & n.s. \\
\hline \multirow[t]{2}{*}{ Solitary or multiple } & Solitary (\%) & $25(30.1)$ & $30(34.9)$ & n.s. \\
\hline & Multiple (\%) & $58(69.9)$ & $56(65.1)$ & \\
\hline
\end{tabular}

GPX2: Glutathione peroxidase 2, n.s.: not significant.

${ }^{* * * *} p<0.0001$ statistically significant.

Table 2: Univariate and multivariate analyses of baseline and GPX2 expression parameters, and progression free survival in 169 TUR patients

\begin{tabular}{|c|c|c|c|c|c|c|}
\hline \multirow[t]{2}{*}{ Parameters } & \multicolumn{3}{|c|}{ Univariate } & \multicolumn{3}{|c|}{ Multivariate } \\
\hline & HR & $95 \% \mathrm{CI}$ & $p$ value & HR & $95 \% \mathrm{CI}$ & $p$ value \\
\hline Age, $72 \leq$ vs. $<71$ & 1.04 & $0.57-1.90$ & 0.89 & 0.92 & $0.51-1.72$ & 0.83 \\
\hline $\begin{array}{l}\text { Gender, } \\
\text { male vs. female }\end{array}$ & 0.50 & $0.27-0.93$ & $0.03^{*}$ & 0.53 & $0.28-1.02$ & 0.06 \\
\hline $\begin{array}{l}\text { Urine cytology, positive and suspicious } \\
\text { positive vs. negative }\end{array}$ & 4.90 & $1.52-15.9$ & $0.0079^{* *}$ & 3.43 & $0.99-11.9$ & 0.051 \\
\hline Tumor multiplicity, multiple vs. solitary & 1.86 & $0.92-3.78$ & 0.09 & 1.58 & $0.76-3.27$ & 0.22 \\
\hline Tumor grade, high vs. low & 4.0 & $0.97-16.5$ & 0.06 & 1.32 & $0.28-6.22$ & 0.72 \\
\hline Concomitant of CIS, yes vs. no & 0.90 & $0.12-6.53$ & 0.92 & 0.66 & $0.09-4.92$ & 0.69 \\
\hline Expression of GPX2, higher vs. lower & 0.41 & $0.22-0.78$ & $0.0061^{* *}$ & 0.49 & $0.25-0.97$ & $0.039^{*}$ \\
\hline
\end{tabular}

CIS: Carcinoma in situ, GPX2: Glutathione peroxidase 2, TUR: Transurethral resection of bladder cancer, HR: Hazards ratio, CI: Confidence interval. ${ }^{*} p<0.05,{ }^{* *} p<0.01$ indicates a significant difference.

clarified. In the present study, we found that GPX2 expression was elevated by PEITC, which promotes bladder carcinogenesis, in normal epithelium in a twostage rat urinary bladder carcinogenesis model. In human gastrointestinal tissue, bacterial infection can enhance GPX expression in initiated cells [27], which is thought to be required for antioxidant defense against $\mathrm{H}_{2} \mathrm{O}_{2}$ or other hydroperoxides, resulting in prevention of tumor promotion $[17,28,29]$. Thus, the findings from this study suggest that similar to the mechanisms observed in the gastrointestinal tract, activation of the glutathione redox system in the early stage of carcinogenesis could protect from promotion of bladder cancer development.

To date, the majority of the reports have described GPX2 as an anti-inflammatory and anti-carcinogenic enzyme. Oxidative stress is generally considered to contribute to the promotion of carcinogenesis. Therefore, reduction of cellular oxidation by GPX up-regulation was expected to prevent against tumor promotion. However, several reports including our previous study described that a high GPX2 expression supported the growth of cancer cells by facilitating their proliferation via inhibition of oxidative damage-induced apoptosis [15, 23, 30]. In line with these studies, we also demonstrated here that suppression of GPX2 by siRNA induced as caspasedependent apoptosis and a decrease in intracellular ROS level in in vitro (Figure 4). Our findings suggest that upregulation of GPX2 is in fact associated with bladder cancer development via its role in regulation of apoptosis and oxidative stress. This is further supported by our study 
using a rat carcinogenesis model whereby the expression level of Gpx2 was significantly increased in PNHP and pure UC as compared to normal epithelium (Figure 1). These results suggest that once carcinogenic abnormalities had accumulated in normal epithelium, there is progressive increase in expression of GPX2 from PNHP to UC. Overexpression of GPX2 may facilitate uncontrolled cell proliferation, thus, GPX2 appears to provide a selective advantage for pure UC cells and support further malignant growth. Further research is necessary to delineate the upstream regulatory mechanisms that control GPX2 expression.

Recently, the prognostic significance of GPX2 in human malignancies was reported [31-36], and only one report has described that low expression level of GPX2 is associated with poorer prognosis in bladder cancer [26].
Our novel findings demonstrated that GPX2 expression was inversely correlated with both the Ki67 labeling index and the expression of P53, a tumor suppressor gene, that is frequently overexpressed or amplified in invasive higher stage bladder cancer (Figure 3A-3K). Yan and Chen [30] reported that the protective function of GPX2 is P53 dependent, and deficiency of GPX2 promotes susceptibility to oxidative stress-induced apoptosis in MCF7 cells, a human breast cancer cell line. It was also reported that cells with GPX2 knock-down had a higher capability to invade and migrate than the GPX2expressing controls in colon cancer. Therefore, an increase in P53 in invasive tumors may also bring about decrease in GPX2 expression along with suppression of its protective function. In addition, our results also demonstrated that pure UC patients with low level of GPX2 expression in
A

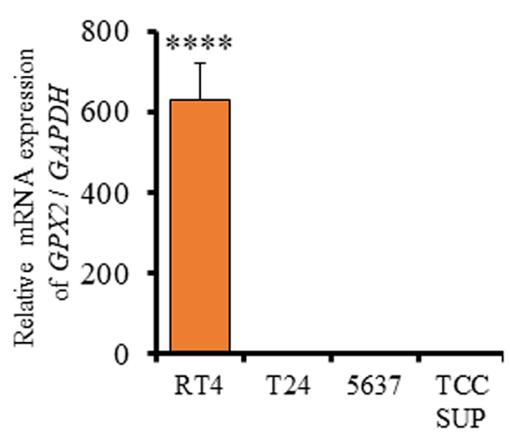

$\mathrm{D}$

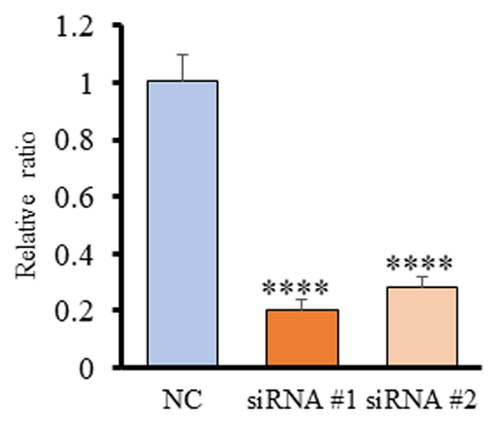

B

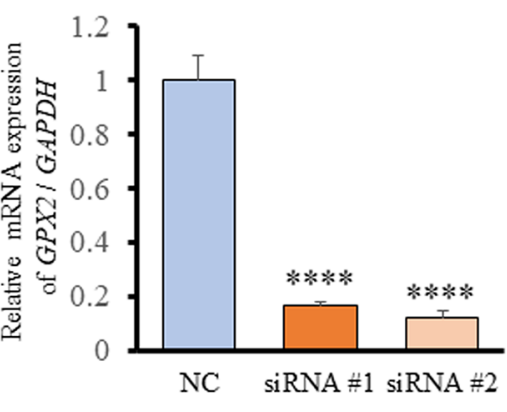

$\mathrm{E}$

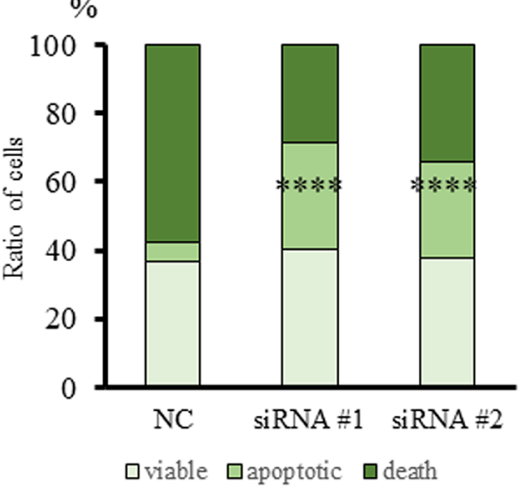

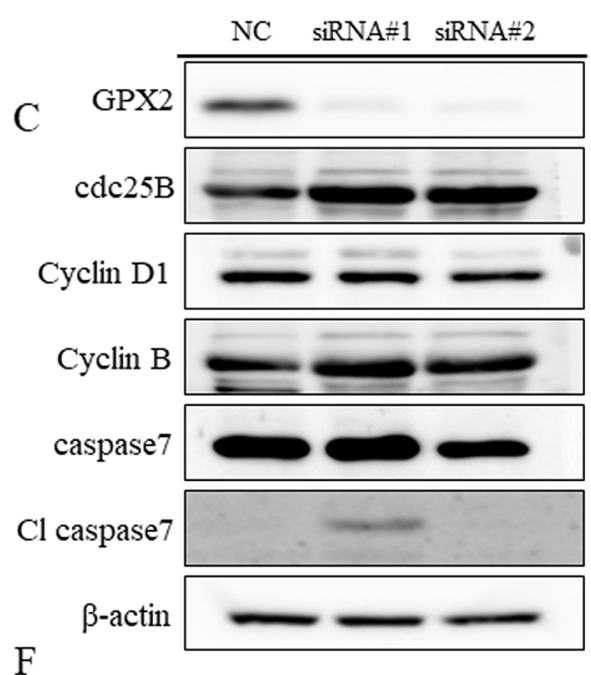

$\mathrm{F}$

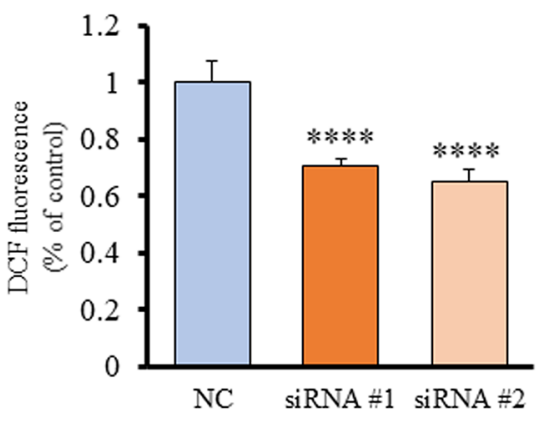

Figure 4: Expression of GPX2 in human bladder cancer cell lines, and GPX2 siRNA transfection in RT4 cells. (A) GPX2 mRNA expression in human bladder cell lines, RT4, T24, 5637, and TCCSUP, was assessed by qRT-PCR. The mRNA expression level of GPX2 in RT4 cells, established from low grade UC, was significantly higher than in other cell lines established from invasive high grade UC. Mean $\pm \mathrm{SD} ;{ }^{* * * *} p<0.0001$. (B) mRNA expression level of GPX2 in RT4 cells was confirmed by qRT-PCR 2 days after transfection with two different GPX2-targeting and negative control (NC) siRNAs. Mean $\pm \mathrm{SD} ;{ }^{* * * *} p<0.0001$. (C) Western blotting analyses at five days after siRNA transfection of RT4 cells. The expression of GPX2 was reduced, but that of cdc25B, cyclin D1, cyclin B, caspase 7, and caspase 3 were not changed. $\beta$-actin was used as internal loading control. (D) Proliferation rate of RT4 cells following transfection with GPX2targeting and NC siRNAs. Mean $\pm \mathrm{SD} ;{ }^{* * * *} p<0.0001$. (E) Guava ${ }^{\circledR}$ apoptosis analysis of RT4 cells after siRNA transfection shows that $G P X 2$ knock-down induced apoptosis. Mean; ${ }^{* * * *} p<0.0001$. (F) DCFH-DA assay was used to quantify intracellular ROS levels after knock-down of $G P X 2$ by siRNA in RT4 cells. Mean $\pm \mathrm{SD} ;{ }^{* * * *} p<0.0001$. 
TUR specimens had significantly poorer PFS, CSS, and OS as compared to patients with high level (Table 1, Figure 3L-3N). From our findings of the role of GPX2 in bladder cancer, we propose that GPX2 may serve as a prognostic biomarker for pure UC patients.

In addition to this, we found in this study that GPX2 was overexpressed in UC with SqD using an animal model, and there were some clinical cases with strong GPX2 expression in UC with SqD using radical cystectomy specimen (Figures 1-2). SqD, defined by the presence of intercellular bridges and/or keratinization, is the most common type of divergent differentiation, occurring in as many as $40 \%$ of invasive UC $[37,38]$. Limited reports have shown that $\mathrm{SqD}$ can predict reduced responsiveness to radiation or chemotherapy, but to date, no report has described the expression level and the role of GPX2 in SqD of UC. It has previously been shown that GPX2 protein is overexpressed in neoplastic transformation of squamous epithelial cells, Barrett's esophagus, and esophageal squamous cell carcinoma [39]. However, the mechanisms of GPX2 overexpression in those tumors are unclear. Yan and Chen [30] reported that GPX2 expression is regulated by $\Delta \mathrm{Np} 63 \gamma$, and GPX2 overexpression can inhibit the apoptotic response of cancer cells to oxidative stress. Serewko et al. [39] revealed that GPX2 expression was induced in human oral epithelial cells during squamous cell carcinoma development, among other alterations in genes that were involved in tissue remodeling, life span, as well as growth and differentiation controls. These mechanisms may also contribute to $\mathrm{SqD}$ of bladder cancer. In addition, in vivo analyses of the $\mathrm{BBN}$-induced rat bladder cancer model following transplantation of BC31 cells with Gpx2 knockdown showed that tumor growth, $\mathrm{SqD}$, angiogenesis were all suppressed, and caused the induction of apoptosis (Figure 6). These results suggested that GPX2 may be an important differentiation biomarker, and a potential target for uncontrollable $\mathrm{UC}$ with $\mathrm{SqD}$ after radiation or chemotherapy. Further investigation is necessary to validate these findings.

In conclusion, our study demonstrated that GPX2 was enhanced in UC and may play an important role in
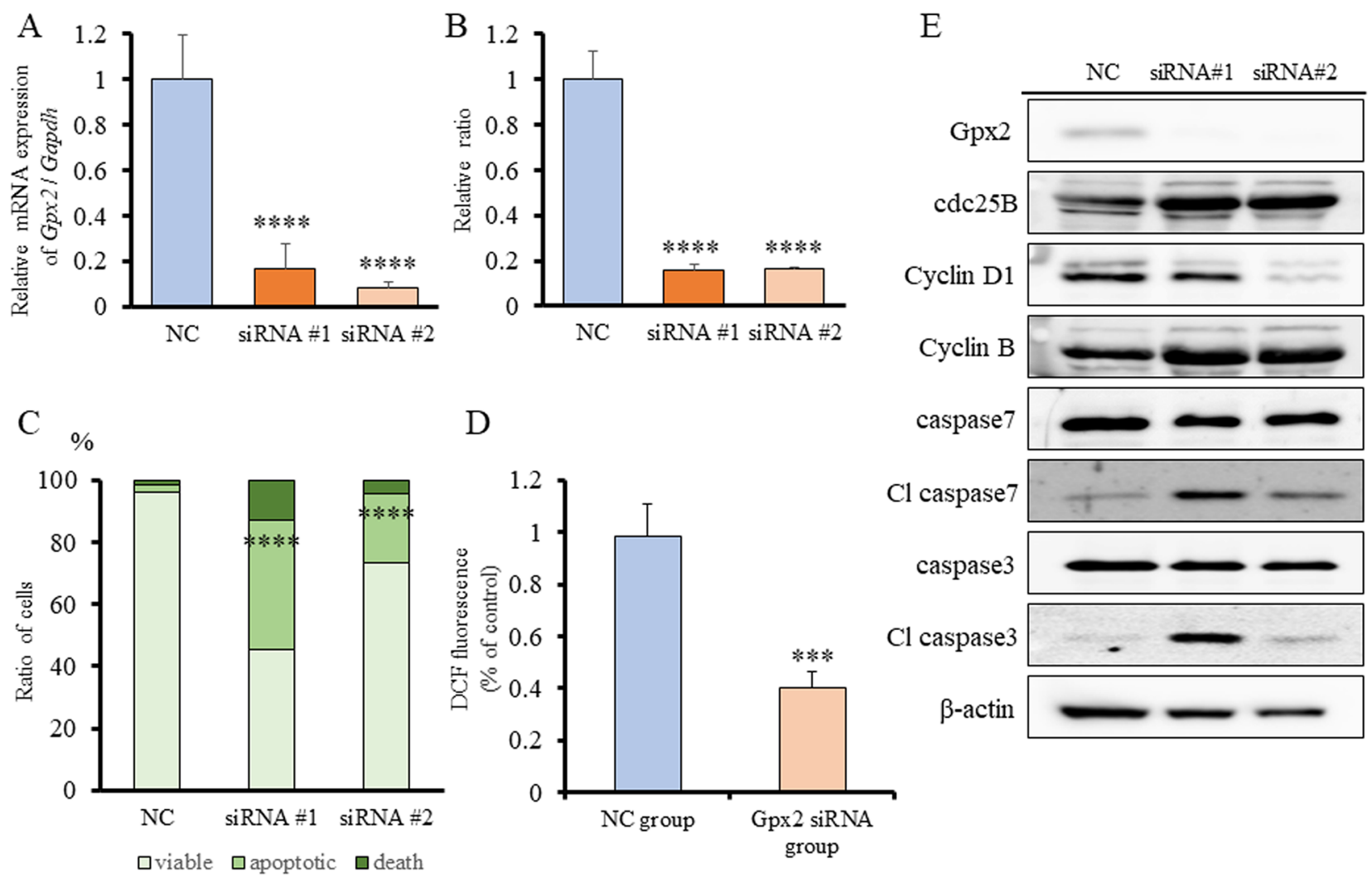

Figure 5: Gpx2 siRNA transfection and ROS signals in BC31 cells. (A) mRNA expression level of Gpx2 in BC31 cells was confirmed by qRT-PCR 2 days after transfection with two different Gpx2-targeting and negative control (NC) siRNAs. Mean \pm SD; ${ }^{* * * *} p<0.0001$. (B) Proliferation rate of BC31 cells treated with Gpx2-targeting and NC siRNAs at 5 days after siRNA transfection. Mean \pm SD; ${ }^{* * * *} p<0.0001$. (C) Guava ${ }^{\circledR}$ apoptosis analysis of BC31 cells after siRNA transfection shows that Gpx2 knock-down induced apoptosis. Mean; ${ }^{* * * *} p<0.0001$. (D) DCFH-DA assay was used to quantify intracellular ROS levels after knock-down of Gpx2 by siRNA in BC31 cells. Mean $\pm \mathrm{SD} ;{ }^{* * *} p<0.001$. (E) Western blotting analyses at 5 days after siRNA transfection of BC31 cells. The expression of Gpx 2 was reduced, but that of cdc25B, cyclin D1, cyclin B, caspase 7, and caspase 3 were not changed. $\beta$-actin was used as internal loading control. 

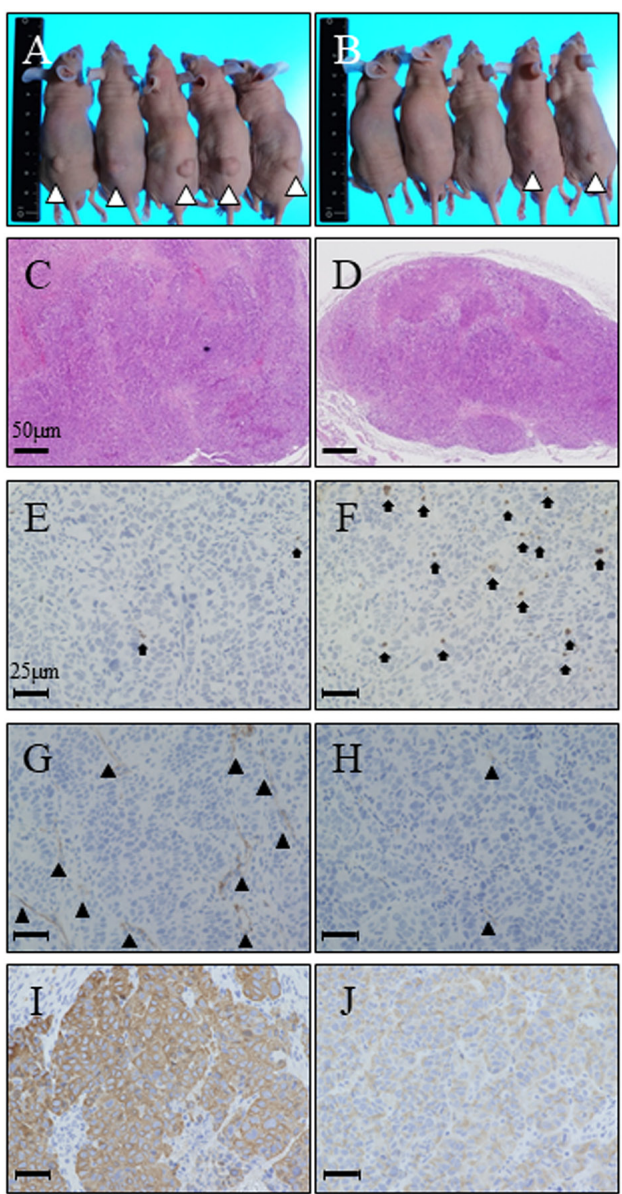
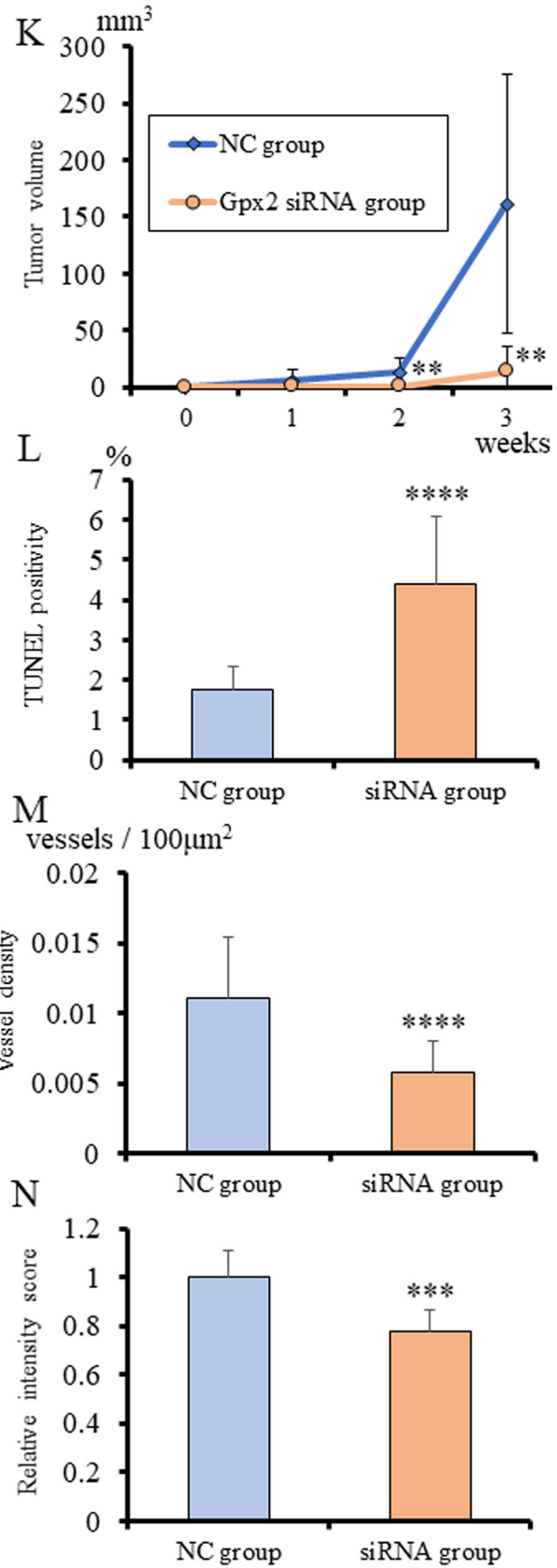

Figure 6: Inhibition of Gpx2 attenuated subcutaneous BC31 tumor growth, induced apoptosis, and decreased CK14 expression in vivo. (A, B) Morphology of subcutaneous tumors at 3 weeks after transplantation. Tumors derived from BC31 cells transfected with negative control (NC) (A) and Gpx2-targeting (B) siRNAs. (C, D) HE staining of subcutaneous tumors derived from BC31 cells transfected with $N C$ - (C) and Gpx2-targeting (D) siRNAs. (E, F) Representative TUNEL staining for apoptosis in tumors derived from BC31 cells transfected with NC (E) and Gpx2-targeting (F) siRNAs. Black arrows indicate TUNEL-positive cells. (G, H) Representative immunohistochemistry for $\mathrm{CD} 31$ in tumors derived from $\mathrm{BC} 31$ cells transfected with $\mathrm{NC}(\mathrm{G})$ and Gpx2-targeting $(\mathrm{H})$ siRNAs. Black arrowhead indicates CD31-positive vessel. (I, J) Representative immunohistochemistry for CK14 in tumors derived from BC31 cells transfected with NC (I) and Gpx2-targeting (J) siRNAs. (K) Tumor growth was significantly inhibited in mice following transplantation of BC31 cells transfected with Gpx2-targeting siRNA as compared to NC. Mean \pm SD; ${ }^{* *} p<0.01$. (L) TUNEL assay was performed on tumors derived from $\mathrm{BC} 31$ cells transfected with Gpx2-targeting and NC siRNAs, and quantified as mean TUNEL labeling percentage based on at least 5 randomly selected high-power microscope fields per individual. Mean \pm SD; ${ }^{* * * *} p<0.0001$. (M) Quantification of immunohistochemical intensity of CD31. Positivity was quantified as mean number of vessels $/ \mathrm{mm}^{2}$ based on at least 5 randomly selected high-power microscope fields per individual. Mean $\pm \mathrm{SD}$; ${ }^{* * * *} p<0.0001$. (N) Quantification of immunohistochemical intensity of CK14. Positivity was quantified as mean intensity score based on at least 5 randomly selected high-power microscope fields per individual. Mean $\pm \mathrm{SD} ;{ }^{* * *} p<0.001$. Nuclei were counterstained with hematoxylin. 
the proliferation of UC with SqD. Further, higher GPX2 expression was associated with better prognosis in pure UC patients. These findings indicated that GPX2 may be one of the essential biomarkers or therapeutic targets for bladder cancer, and more randomized control trials should be performed in the near future to verify this.

\section{MATERIALS AND METHODS}

\section{BBN and PEITC-induced bladder carcinogenesis rat model}

In a previous study, 6-week-old male F344 rats were given $0.05 \% \mathrm{BBN}$ in the drinking water for 4 weeks as initiation [40]. Three days after completion of the initiation, a diet containing $0 \%, 0.01 \%$, or $0.05 \%$ PEITC was given for 32 weeks. All bladder tissues obtained from this previous study were reprocessed [40, 41], and neoplastic lesions were reevaluated by experienced pathologists (A. N-I, S. S.).

\section{Human radical cystectomy specimens}

Radical cystectomy specimens were obtained from Nagoya City University Hospital between 2010 and 2014. All specimens were obtained after the patients had provided written informed consent for the use of their tissues, according to an Institutional Review Board-approved protocol, and the approval number was NCU-893. All cases were reevaluated by experienced pathologists.

\section{Immunohistochemical analyses}

Deparaffinized formalin-fixed tissues were incubated with 1:100 diluted anti-GPX2, 1:100 diluted anti-Ki67 (Dako, Glostrup, Denmark), or 1:500 diluted anti-P53 antibody (Leica Biosystems, Wetzlar, Germany) [23], and the rat tissues were also incubated with 1:100 diluted anti-CD31 (Abcam, Cambridge, UK) or 1:100 diluted anti-CK14 (Leica Biosystems) antibody. Antibody binding was visualized by a conventional immunostaining method using an autoimmunostaining apparatus as described previously [21, 23] (HX System, Ventana, Tuscon, AZ).

In the analysis of human TUR specimens, the intensity score of GPX2 expression was evaluated in carcinoma lesions from each patient. In the analysis of the intensity of GPX2 cytoplasmic immunoreactivity during the initiation period in the animal model, the raw intensity data for normal epithelium in each group were compared. Next, the intensity of GPX2 cytoplasmic immunoreactivity in PNHP and UC lesions, which correspond to the promotion period, from the $\mathrm{BBN}+0.01 \%$ PEITC group was calculated. Further, the intensity of GPX2 cytoplasmic immunoreactivity in PNHP, UC lesions, and UC with $\mathrm{SqD}$ lesions from the $\mathrm{BBN}+0.05 \%$ PEITC group was analyzed. All analyses were performed using the BZ-9000 multifunctional microscope and the associated analysis software (Keyence Japan, Osaka, Japan). The evaluations were repeated 5 times in each patient, and the average intensity score in each lesion was calculated.

\section{Prognostic analysis of pure UC patients using TUR specimens}

Between April 2007 and March 2012, 169 wellcharacterized patients were newly diagnosed with pure UC originating from the urinary bladder using the initial TUR at Nagoya City University Hospital. The clinical course of these patients with bladder cancer is listed in Table 1. In the analysis of TUR specimens, we calculated the average expression score in each patient, and the median intensity score (96.7) was used as the cutoff to dichotomize the study cohort using the following categories: low level GPX2 expression group (average intensity score $<96.7$ ) and high level GPX2 expression group (average intensity score $\geq 96.7$ ). Two pathologists re-evaluated hematoxylin and eosin (HE) sections of all cases, and the intensity scores of GPX2 immunostaining were evaluated using the Biorevo BZ-9000 microscope and the associated software (KEYENCE, Osaka, Japan).

\section{Cell culture and treatments}

The human bladder cancer cell lines, including a low grade urothelial carcinoma cell line (RT4) [42-46], and high grade urothelial carcinoma cell lines (T24, 5637, and TCCSUP), purchased from American Type Culture Collection (Manassas, VA), and rat bladder cancer with $\mathrm{SqD}$ cell line, $\mathrm{BC} 31$, which was established from the BBN-induced rat bladder cancer model [24, 25], were cultured as described previously [23]. All experiments were performed in triplicate.

\section{RNA preparation and $q R T-P C R$}

Total RNA was extracted using Isogen (Nippon Gene, Tokyo, Japan). For the measurement of mRNA level, qRTPCR was performed as previously described [23]. Primer sequences were 5'-GACACGAGGAAACCGAAGCA-3' and 5'-GGCCCTTCACAACGTCT-3' for rat Gpx 2 ; 5'-GCCTCCTTAAAGTTGCCATA-3' and 5'-GCCCAGAGCTTACCCA-3' for human GPX2; and 5'-GCATCCTGCACCACCAACTG-3' and 5'-GCCTGCTTCACCACCTTCTT-3' for glyceraldehyde3-phosphate dehydrogenase (GAPDH).

\section{Western blotting analysis}

Cells were lysed in SDS buffer, and $10 \mu \mathrm{g}$ of protein was resolved in $12 \%$ polyacrylamide gels and transferred onto Hybond ECL membranes (GE Healthcare, Piscataway NJ). GPX2, cyclin B (BD Bioscience, Franklin 
lakes, NJ), as well as cyclin D1, cdc 25B, cleaved caspase 3 , caspase 3, caspase 7), and cleaved caspase 7 (Cell Signaling Technology, Beverly, MA) antibodies were used to assess their protein expression levels. Betaactin expression was evaluated to confirm equal amount of protein loading using a monoclonal anti-beta-actin antibody (Sigma-Aldrich, St. Louis, MO).

\section{In vitro siRNA transfection and cell growth assay}

siRNAs targeting rat and human $G P X 2$ sequences were obtained (Thermo Fischer Scientific, Boston, MA). RT4 $\left(2 \times 10^{5}\right)$ and BC31 $\left(5 \times 10^{4}\right)$ cells were seeded in six-well plates and transfected with $30 \mathrm{nM}$ siRNA using LipofectAMINE RNAiMAX (Thermo Fischer Scientific) according to the manufacturer's protocol. Non-targeting siRNA with no significant homology to any known rat and human genes was also used as a negative control (NC). Confirmation of GPX2 knock-down was performed on the second day after transfection. For monitoring of cell growth, cells were trypsinized on day 5 after transfection and then counted.

\section{Flow cytometry analysis}

RT4 and BC31 cells $\left(2 \times 10^{5}\right)$ were transfected with GPX2 siRNA for $72 \mathrm{~h}$ then cell suspensions were prepared and stained with Guava ${ }^{\circledR}$ ViaCount reagent and propidium iodide according to the Guava ${ }^{\circledR}$ Assay protocol (Guava Technologies, Hayward, CA). Apoptotic analysis and cell cycle phase distributions were determined on a Guava ${ }^{\mathbb{B}}$ PCA Instrument using the CytoSoft Software.

\section{Measurement of intracellular ROS level}

For the measurement of intracellular ROS level, the DCFH-DA assay was performed as previously described [23]. The data were normalized by the proliferation rate as measured by the WST-1 assay using the WST-1 Cell Proliferation Reagent (Roche, Basal, Switzerland).

\section{In vivo studies using subcutaneously-injected BC31 cells}

Six-week-old male KSN/nu-nu nude mice were obtained from Nippon SLC and maintained as previously described [23]. Twenty-four hours after Gpx2 siRNA transfection into $\mathrm{BC} 31$ cells, they were trypsinized and suspended in serum-free DMEM, after which $1 \times 10^{5}$ cells per mouse were injected subcutaneously into five normal and five castrated mice. NC-siRNA treated cells were also injected as controls. Tumor volume was calculated every week, and three weeks after inoculation, the four groups of mice were sacrificed. Tumor volume was calculated using the formula, $\mathrm{V}=\left(\mathrm{A}_{\left.\mathrm{x} \mathrm{B}^{2}\right)}\right) / 2$, where $\mathrm{V}$ represented volume in $\mathrm{mm}^{3}$, and $\mathrm{A}$ and $\mathrm{B}$ represented the long and the short diameter in $\mathrm{mm}$, respectively.
All animal experiments were performed under protocols approved by the Institutional Animal Care and Use Committee of Nagoya City University School of Medical Sciences, and the approval number was H25M-54.

\section{TUNEL assay}

Apoptotic cells in deparaffinized tissues were detected by the terminal deoxy nucleotidyl transferasemediated dUTP nick end labeling (TUNEL) assay performed using an In situ Apoptosis Detection Kit from Takara (Otsu, Japan) as per the manufacturer's protocol. Five randomly selected microscopic fields in each group were used to calculate the relative ratio of TUNELpositive cells.

\section{Statistical analysis}

Differences between the various parameters were assessed using Student's $t$-test, ANOVA, Tukey's posthoc methods, Kruskal-Wallis test, and chi-square test, whichever was appropriate. The PFS, CSS, and overall survival (OS) curves were estimated by the Kaplan-Meier method, and log-rank test was applied to compare survival between groups. To identify prognostic factors for PFS after the TUR, we evaluated seven variables (age, gender, urine cytology before the TUR, tumor multiplicity, tumor grade, concomitant carcinoma in situ [CIS] and GPX2 expression level) by univariate and multivariate analyses using the Cox proportional hazard regression model. A p-value $<0.05$ was considered to indicate a statistically significant difference. Statistical analyses were performed using the EZR software (Saitama Medical Center, Jichi Medical University, Yakushiji, Japan).

\section{CONFLICTS OF INTEREST}

There are no potential conflicts of interest.

\section{FUNDING}

This work was supported in part by a Grant-Aid from the Ministry of Education, Culture, Sports Science and Technology of Japan [grant number 17K11153].

\section{REFERENCES}

1. Ferlay J, Soerjomataram I, Dikshit R, Eser S, Mathers C, Rebelo M, Parkin DM, Forman D, Bray F. Cancer incidence and mortality worldwide: sources, methods and major patterns in GLOBOCAN 2012. Int J Cancer. 2015; 136:E359-386.

2. Marcus PM, Hayes RB, Vineis P, Garcia-Closas M, Caporaso NE, Autrup H, Branch RA, Brockmoller J, Ishizaki T, Karakaya AE, Ladero JM, Mommsen S, 
Okkels H, et al. Cigarette smoking, N-acetyltransferase 2 acetylation status, and bladder cancer risk: a case-series meta-analysis of a gene-environment interaction. Cancer Epidemiol Biomarkers Prev. 2000; 9:461-467.

3. Zeegers MP, Kellen E, Buntinx F, van den Brandt PA. The association between smoking, beverage consumption, diet and bladder cancer: a systematic literature review. World J Urol. 2004; 21:392-401.

4. Perse M, Injac R, Erman A. Oxidative status and lipofuscin accumulation in urothelial cells of bladder in aging mice. PLoS One. 2013; 8:e59638.

5. Cao M, Mu X, Jiang C, Yang G, Chen H, Xue W. Singlenucleotide polymorphisms of GPX1 and MnSOD and susceptibility to bladder cancer: a systematic review and meta-analysis. Tumour Biol. 2014; 35:759-764.

6. Ishaq M, Khan MA, Sharma K, Sharma G, Dutta RK, Majumdar S. Gambogic acid induced oxidative stress dependent caspase activation regulates both apoptosis and autophagy by targeting various key molecules (NF-kappaB, Beclin-1, p62 and NBR1) in human bladder cancer cells. Biochim Biophys Acta. 2014; 1840:3374-3384.

7. Kawanishi S, Ohnishi S, Ma N, Hiraku Y, Oikawa S, Murata M. Nitrative and oxidative DNA damage in infection-related carcinogenesis in relation to cancer stem cells. Genes Environ. 2016; 38:26.

8. Qiu M, Chen L, Tan G, Ke L, Zhang S, Chen H, Liu J. A reactive oxygen species activation mechanism contributes to JS-K-induced apoptosis in human bladder cancer cells. Sci Rep. 2015; 5:15104.

9. Liu Y, Lan L, Huang K, Wang R, Xu C, Shi Y, Wu X, Wu Z, Zhang J, Chen L, Wang L, Yu X, Zhu H, et al. Inhibition of Lon blocks cell proliferation, enhances chemosensitivity by promoting apoptosis and decreases cellular bioenergetics of bladder cancer: potential roles of Lon as a prognostic marker and therapeutic target in baldder cancer. Oncotarget. 2014; 5:11209-11224. https://doi.org/10.18632/oncotarget.2026.

10. Zeng T, Peng L, Chao H, Xi H, Fu B, Wang Y, Zhu Z, Wang G. IRE1alpha-TRAF2-ASK1 complex-mediated endoplasmic reticulum stress and mitochondrial dysfunction contribute to CXC195-induced apoptosis in human bladder carcinoma T24 cells. Biochem Biophys Res Commun. 2015; 460:530-536.

11. Arthur JR. The glutathione peroxidases. Cell Mol Life Sci. 2000; 57:1825-1835.

12. Brigelius-Flohe R, Maiorino M. Glutathione peroxidases. Biochim Biophys Acta. 2013; 1830:3289-3303.

13. Margis R, Dunand C, Teixeira FK, Margis-Pinheiro M. Glutathione peroxidase family - an evolutionary overview. FEBS J. 2008; 275:3959-3970.

14. Brigelius-Flohe R. Tissue-specific functions of individual glutathione peroxidases. Free Radic Biol Med. 1999; 27:951-965.
15. Brigelius-Flohe R, Kipp A. Glutathione peroxidases in different stages of carcinogenesis. Biochim Biophys Acta. 2009; 1790:1555-1568.

16. Konno S, Chu K, Feuer N, Phillips J, Choudhury M. Potent anticancer effects of bioactive mushroom extracts (phellinus linteus) on a variety of human cancer cells. J Clin Med Res. 2015; 7:76-82.

17. Al-Taie OH, Uceyler N, Eubner U, Jakob F, Mork H, Scheurlen M, Brigelius-Flohe R, Schottker K, Abel $\mathrm{J}$, Thalheimer A, Katzenberger T, Illert B, Melcher $\mathrm{R}$, et al. Expression profiling and genetic alterations of the selenoproteins GI-GPx and SePP in colorectal carcinogenesis. Nutr Cancer. 2004; 48:6-14.

18. Brigelius-Flohe R, Muller M, Lippmann D, Kipp AP. The yin and yang of nrf2-regulated selenoproteins in carcinogenesis. Int J Cell Biol. 2012; 2012:486147.

19. Chu FF, Doroshow JH, Esworthy RS. Expression, characterization, and tissue distribution of a new cellular selenium-dependent glutathione peroxidase, GSHPx-GI. J Biol Chem. 1993; 268:2571-2576.

20. Brigelius-Flohe R, Kipp AP. Physiological functions of GPx2 and its role in inflammation-triggered carcinogenesis. Ann N Y Acad Sci. 2012; 1259:19-25.

21. Naiki-Ito A, Asamoto M, Hokaiwado N, Takahashi S, Yamashita H, Tsuda H, Ogawa K, Shirai T. Gpx2 is an overexpressed gene in rat breast cancers induced by three different chemical carcinogens. Cancer Res. 2007; 67:11353-11358.

22. Suzuki S, Pitchakarn P, Ogawa K, Naiki-Ito A, Chewonarin T, Punfa W, Asamoto M, Shirai T, Takahashi S. Expression of glutathione peroxidase 2 is associated with not only early hepatocarcinogenesis but also late stage metastasis. Toxicology. 2013; 311:115-123.

23. Naiki T, Naiki-Ito A, Asamoto M, Kawai N, Tozawa K, Etani T, Sato S, Suzuki S, Shirai T, Kohri K, Takahashi $\mathrm{S}$. GPX2 overexpression is involved in cell proliferation and prognosis of castration-resistant prostate cancer. Carcinogenesis. 2014; 35:1962-1967.

24. Asamoto M, Takahashi S, Imaida K, Shirai T, Fukushima $\mathrm{S}$. Increased gap junctional intercellular communication capacity and connexin 43 and 26 expression in rat bladder carcinogenesis. Carcinogenesis. 1994; 15:2163-2166.

25. Asamoto M, Toriyama-Baba T, Krutovskikh V, Cohen SM, Tsuda H. Enhanced tumorigenicity of rat bladder squamous cell carcinoma cells after abrogation of gap junctional intercellular communication. Jpn J Cancer Res. 1998; 89:481-486.

26. Chang IW, Lin VC, Hung $\mathrm{CH}$, Wang $\mathrm{HP}$, Lin $\mathrm{YY}$, Wu WJ, Huang CN, Li CC, Li WM, Wu JY, Li CF. GPX2 underexpression indicates poor prognosis in patients with urothelial carcinomas of the upper urinary tract and urinary bladder. World J Urol. 2015; 33:1777-1789.

27. Esworthy RS, Yang L, Frankel PH, Chu FF. Epitheliumspecific glutathione peroxidase, Gpx2, is involved in the 
prevention of intestinal inflammation in selenium-deficient mice. J Nutr. 2005; 135:740-745.

28. Banning A, Kipp A, Schmitmeier S, Lowinger M, Florian S, Krehl S, Thalmann S, Thierbach R, Steinberg P, Brigelius-Flohe R. Glutathione peroxidase 2 inhibits cyclooxygenase-2-mediated migration and invasion of HT-29 adenocarcinoma cells but supports their growth as tumors in nude mice. Cancer Res. 2008; 68:9746-9753.

29. Florian S, Wingler K, Schmehl K, Jacobasch G, Kreuzer OJ, Meyerhof W, Brigelius-Flohe R. Cellular and subcellular localization of gastrointestinal glutathione peroxidase in normal and malignant human intestinal tissue. Free Radic Res. 2001; 35:655-663.

30. Yan W, Chen X. GPX2, a direct target of p63, inhibits oxidative stress-induced apoptosis in a p53-dependent manner. J Biol Chem. 2006; 281:7856-7862.

31. Chiu ST, Hsieh FJ, Chen SW, Chen CL, Shu HF, Li H. Clinicopathologic correlation of up-regulated genes identified using cDNA microarray and real-time reverse transcription-PCR in human colorectal cancer. Cancer Epidemiol Biomarkers Prev. 2005; 14:437-443.

32. Emmink BL, Laoukili J, Kipp AP, Koster J, Govaert KM, Fatrai S, Verheem A, Steller EJ, Brigelius-Flohe R, Jimenez CR, Borel Rinkes IH, Kranenburg O. GPx2 suppression of $\mathrm{H} 2 \mathrm{O} 2$ stress links the formation of differentiated tumor mass to metastatic capacity in colorectal cancer. Cancer Res. 2014; 74:6717-6730.

33. Lei Z, Tian D, Zhang C, Zhao S, Su M. Clinicopathological and prognostic significance of GPX2 protein expression in esophageal squamous cell carcinoma. BMC Cancer. 2016; 16:410.

34. Liu C, He X, Wu X, Wang Z, Zuo W, Hu G. Clinicopathological and prognostic significance of GPx2 protein expression in nasopharyngeal carcinoma. Cancer Biomark. 2017; 19:335-340.

35. Liu D, Sun L, Tong J, Chen X, Li H, Zhang Q. Prognostic significance of glutathione peroxidase 2 in gastric carcinoma. Tumour Biol. 2017; 39:1010428317701443.

36. Liu T, Kan XF, Ma C, Chen LL, Cheng TT, Zou ZW, Li Y, Cao FJ, Zhang WJ, Yao J, Li PD. GPX2 overexpression indicates poor prognosis in patients with hepatocellular carcinoma. Tumour Biol. 2017; 39:1010428317700410.

37. Wasco MJ, Daignault S, Zhang Y, Kunju LP, Kinnaman M, Braun T, Lee CT, Shah RB. Urothelial carcinoma with divergent histologic differentiation (mixed histologic features) predicts the presence of locally advanced bladder cancer when detected at transurethral resection. Urology. 2007; 70:69-74.

38. Kim SP, Frank I, Cheville JC, Thompson RH, Weight CJ, Thapa P, Boorjian SA. The impact of squamous and glandular differentiation on survival after radical cystectomy for urothelial carcinoma. J Urol. 2012; 188:405-409.

39. Serewko MM, Popa C, Dahler AL, Smith L, Strutton GM, Coman W, Dicker AJ, Saunders NA. Alterations in gene expression and activity during squamous cell carcinoma development. Cancer Res. 2002; 62:3759-3765.

40. Ogawa K, Hirose M, Sugiura S, Cui L, Imaida K, Ogiso T, Shirai T. Dose-dependent promotion by phenylethyl isothiocyanate, a known chemopreventer, of two-stage rat urinary bladder and liver carcinogenesis. Nutr Cancer. 2001; 40:134-139.

41. Akagi K, Sano M, Ogawa K, Hirose M, Goshima H, Shirai T. Involvement of toxicity as an early event in urinary bladder carcinogenesis induced by phenethyl isothiocyanate, benzyl isothiocyanate, and analogues in F344 rats. Toxicol Pathol. 2003; 31:388-396.

42. van der Heijden AG, Jansen CF, Verhaegh G, O'donnell MA, Schalken JA, Witjes JA. The effect of hyperthermia on mitomycin-C induced cytotoxicity in four human bladder cancer cell lines. Eur Urol. 2004; 46:670-674.

43. Kwon DN, Choi YJ, Park JY, Cho SK, Kim MO, Lee HT, $\mathrm{Kim} \mathrm{JH}$. Cloning and molecular dissection of the $8.8 \mathrm{~kb}$ pig uroplakin II promoter using transgenic mice and RT4 cells. J Cell Biochem. 2006; 99:462-477.

44. Mechlin CW, Tanner MJ, Chen M, Buttyan R, Levin RM, Mian BM. Gli2 expression and human bladder transitional carcinoma cell invasiveness. J Urol. 2010; 184:344-351.

45. Kim SJ, Kim JH, Jung HS, Lee TJ, Lee KM, Chang IH. Phosphorylated p70S6K in noninvasive low-grade urothelial carcinoma of the bladder: correlation with tumor recurrence. Asian J Androl. 2014; 16:611-617.

46. Hoffman KL, Lerner SP, Smith CL. Raloxifene inhibits growth of RT4 urothelial carcinoma cells via estrogen receptor-dependent induction of apoptosis and inhibition of proliferation. Horm Cancer. 2013; 4:24-35. 